\title{
Preventative therapies for healthy women at high risk of breast cancer
}

\author{
This article was published in the following Dove Press journal: \\ Cancer Management and Research \\ 17 October 2014 \\ Number of times this article has been viewed
}

\section{Ivana Sestak}

Centre for Cancer Prevention, Wolfson Institute of Preventive Medicine, Queen Mary University of London, Charterhouse Square, London, UK
Correspondence: Ivana Sestak Centre for Cancer Prevention, Wolfson Institute of Preventive Medicine, Queen Mary University of London, Charterhouse Square, London ECIM 6BQ, UK

Email i.sestak@qmul.ac.uk
Abstract: Tamoxifen has been shown to reduce the risk of developing estrogen receptor (ER)-positive breast cancer by at least $50 \%$, in both pre- and postmenopausal women. The current challenge is to find new agents with fewer side effects and to find agents that are specifically suitable for premenopausal women with ER-negative breast cancer. Other selective estrogen receptor modulators (SERMs), such as raloxifene, arzoxifene, and lasofoxifene, have been shown to reduce the incidence of breast cancer by $50 \%-80 \%$. SERMs are interesting agents for the prevention of breast cancer, but longer follow-up is needed for some of them for a complete risk-benefit profile of these drugs. Aromatase inhibitors have emerged as new drugs in the prevention setting for postmenopausal women. In the Mammary Prevention 3 (MAP3) trial, a $65 \%$ reduction in invasive breast cancer with exemestane was observed, and the Breast Cancer Intervention Study-II trial, which compared anastrozole with placebo, reported a $60 \%$ reduction in those cancers. Although SERMs and aromatase inhibitors have been proven to be excellent agents in the preventive setting specifically for postmenopausal women and ER-positive breast cancer, newer agents have to be found specifically for ER-negative breast cancers, which mostly occur in premenopausal women.

Keywords: breast cancer, preventive therapy, selective estrogen receptor modulators, aromatase inhibitors, high-risk women

\section{Introduction}

Breast cancer is by far the most common cancer in women worldwide, with an estimated 1.67 million new cancers diagnosed in 2012. ${ }^{1}$ Breast cancer is associated with a variety of lifestyle choices, such as obesity, later onset of first childbirth, and the use of hormone replacement therapy, which is also increasing in the developing world. Breast cancer still remains the second cause of cancer death in the developed world. There has been a trend toward reduction of breast cancer mortality, due to advanced early detection and better therapeutic strategies. However, breast cancer incidence and mortality have remained extremely high.

The identification of women who are at high risk of developing the disease, which typically means a 5-year breast cancer risk of $1.67 \%$ or higher, is key to chemoprevention of breast cancer. Traditionally, women are categorized as being high risk for breast cancer due to their family history. However, new developments in the ability to predict and modify breast cancer risk have been found. One example is mammographic density, which in terms of population attributable risk, accounts for more breast cancers than family history. ${ }^{2}$ Targeting women at high risk of developing breast cancer identified by biomarkers, such as breast density, atypical hyperplasia, or lobular carcinoma in situ, 
with a high population attributable risk, ${ }^{3}$ and offering them agents that reduce their risk of developing the disease are likely to lead the way in developing this approach to cancer prevention.

Chemoprevention is the use of drugs, vitamins, food supplements, vaccines, or other agents to try to reduce the risk, delay the development, or recurrence of cancer, and it is a promising strategy for cancer prevention. ${ }^{4}$ It is therefore crucial to identify as precisely as possible which types of breast cancers can be prevented by specific agents.

Here, a comprehensive review of breast cancer prevention approaches for women at high risk of developing the disease will be presented. Most will be dedicated to the discussion of selective estrogen receptor modulators (SERMs), of which tamoxifen is the most widely studied and has been used in the past few decades to treat breast cancer; and it has also been shown to reduce the incidence of invasive breast cancer. Furthermore, results have been reported on aromatase inhibitors (AIs) for breast cancer prevention in women at high risk of the disease, which will also be discussed in this overview.

\section{Selective estrogen receptor modulators}

SERMs are chemically diverse compounds with the capability to bind to estrogen receptors (ERs). They have both selective agonist and antagonist abilities on a variety of organs, which contain ERs.

\section{Tamoxifen}

Tamoxifen is a well-known and extensively researched compound. Tamoxifen has been adapted for application in both the treatment and prevention of breast cancer. ${ }^{5,6}$ Four major prevention trials ${ }^{7-15}$ have been completed and published updated results on the use of tamoxifen as a preventive agent (Table 1). Overall, a reduction of $38 \%$ in the risk of breast cancer has been observed. ${ }^{6}$ Although no effect on breast cancers with ER-negative origin has been observed, the results from an overview of all the trials suggest that $50 \%$ of ER-positive breast cancers can be prevented with 5 years of active tamoxifen use. The updated results from the SERM overview have reported that an extended beneficial effect of tamoxifen is observed even after 5 years of treatment completion. ${ }^{16}$

Although tamoxifen has been proven to significantly reduce the incidence of breast cancer, increases in endometrial cancer and venous thromboembolic events are the most serious adverse events of this drug. Overall, both adverse events were increased between 2 and 2.5 fold in tamoxifen users, but analysis of long-term follow-up data has shown that thromboembolic events were not in excess after tamoxifen treatment was stopped. ${ }^{10}$ In summary, tamoxifen prevents ER-positive breast cancer during the first 5 years of treatment and also after treatment cessation. The benefits could persist even longer, and therefore tamoxifen is an attractive chemopreventive option, specifically in premenopausal women, where life expectancy is long.

\section{Raloxifene}

Raloxifene is also a SERM developed for the prevention of osteoporosis in postmenopausal women. Like tamoxifen, it has both estrogen-agonistic effects on the bone and lipid metabolisms and estrogen-antagonistic effects on the endometrial and breast tissues. All the studies investigating raloxifene as a preventive agent for the reduction in breast cancer incidence were initially developed as osteoporosis or cardiovascular prevention trials, and breast cancer incidence was a secondary endpoint.

Four trials have reported their results using raloxifene as a preventive agent (Table 1). Both the Multiple Outcomes of Raloxifene Evaluation ${ }^{17}$ and the Continuing Outcomes Relevant to Evista ${ }^{18}$ reported a significant reduction (65\% and $50 \%$, respectively) in breast cancer overall. Like tamoxifen, an increase in thromboembolic events has been observed with raloxifene, but no significant excess in endometrial cancers or other gynecological problems has been found.

Another study was the Raloxifene Use for The Heart study, ${ }^{19}$ where an overall reduction of $44 \%$ for invasive breast cancer was found with raloxifene, which is similar in size to that seen for tamoxifen in other studies. A direct comparison between tamoxifen and raloxifene was performed in the Study of Tamoxifen and Raloxifene trial. ${ }^{20}$ The efficacy was about 25\% lower for raloxifene compared with tamoxifen, but there were fewer thromboembolic events and gynecological problems with raloxifene. Although raloxifene is widely used in the prevention of osteoporosis, its use in the preventive setting for breast cancer is not common.

\section{Other SERMs}

Two other SERMs (lasofoxifene and arzoxifene) have been investigated in postmenopausal women. The PEARL (Postmenopausal Evaluation and Risk Reduction With Lasofoxifene) trial recruited 8,556 postmenopausal healthy women to three treatment arms: placebo versus $0.25 \mathrm{mg} /$ day lasofoxifene versus $0.5 \mathrm{mg} /$ day lasofoxifene for 5 years in a 1:1:1 ratio (Table 1$){ }^{21}$ 
Table I Details of breast cancer prevention trials

\begin{tabular}{|c|c|c|c|c|c|c|c|}
\hline & $\mathbf{N}$ & $\begin{array}{l}\text { Recruitment } \\
\text { period }\end{array}$ & $\begin{array}{l}\text { Treatment groups and } \\
\text { daily dose }\end{array}$ & $\begin{array}{l}\text { Treatment } \\
\text { duration } \\
\text { (years) }\end{array}$ & & Present status & $\begin{array}{l}\text { Median } \\
\text { follow-up } \\
\text { (months) }\end{array}$ \\
\hline Marsden $^{7,8}$ & $2,47 \mid$ & $1986-96$ & $\begin{array}{l}\text { Placebo }(1,233) \\
\text { Tamoxifen } 20 \mathrm{mg}(1,238)\end{array}$ & $5-8$ & $\begin{array}{l}\text { High risk, family } \\
\text { history }\end{array}$ & $\begin{array}{l}\text { Blinded, further } \\
\text { follow-up }\end{array}$ & $171.6(153.9-184.0)$ \\
\hline IBIS-|',10 & 7,109 & $|992-200|$ & $\begin{array}{l}\text { Placebo }(3,566) \\
\text { Tamoxifen } 20 \mathrm{mg}(3,573)\end{array}$ & 5 & $>2$-fold relative risk & $\begin{array}{l}\text { Blinded, further } \\
\text { follow-up }\end{array}$ & $96(80.1-117.1)$ \\
\hline NSABP-PI $\left.\right|^{13,14}$ & 13,205 & $1992-97$ & $\begin{array}{l}\text { Placebo }(6,707) \\
\text { Tamoxifen } 20 \mathrm{mg}(6,68 \mathrm{I})\end{array}$ & 5 & $>1.6 \% 5$-year risk & $\begin{array}{l}\text { Unblinded, no } \\
\text { follow-up }\end{array}$ & $57.6(35.4-64.9)$ \\
\hline Italian $11,12,15$ & 5,048 & $1992-97$ & $\begin{array}{l}\text { Placebo }(2,708) \\
\text { Tamoxifen } 20 \mathrm{mg}(2,700)\end{array}$ & 5 & $\begin{array}{l}\text { Normal risk, women } \\
\text { with } \\
\text { hysterectomy }\end{array}$ & $\begin{array}{l}\text { Unblinded, } \\
\text { further } \\
\text { follow-up }\end{array}$ & $139.6(\mid 22.0-146.1)$ \\
\hline MORE $^{17} / \mathrm{CORE}^{18}$ & $7,705 / 6,51 I$ & $\begin{array}{l}1994-98 / 1998- \\
2002\end{array}$ & $\begin{array}{l}\text { Placebo }(2,576) \\
\text { Raloxifene } 60 \mathrm{mg}(2,557) / \\
\text { Placebo }(2,576) \\
\text { Raloxifene I } 20 \mathrm{mg}(2,572)\end{array}$ & $4 / 8$ & $\begin{array}{l}\text { Normal risk, } \\
\text { postmenopausal } \\
\text { women with } \\
\text { osteoporosis }\end{array}$ & $\begin{array}{l}\text { Unblinded, no } \\
\text { follow-up }\end{array}$ & 71.3 (47.I-95.4) \\
\hline RUTH ${ }^{19}$ & 10,101 & $1998-2000$ & $\begin{array}{l}\text { Placebo }(5,057) \\
\text { Raloxifene } 60 \mathrm{mg}(5,044)\end{array}$ & 5 & $\begin{array}{l}\text { Normal risk, } \\
\text { postmenopausal } \\
\text { women with } \\
\text { established or } \\
\text { risk of CHD }\end{array}$ & $\begin{array}{l}\text { Unblinded, no } \\
\text { follow-up }\end{array}$ & $66.7(60.1-72.3)$ \\
\hline STAR $^{20}$ & 19,490 & 1999-2004 & $\begin{array}{l}\text { Raloxifene } 60 \text { mg }(9,875) \\
\text { Tamoxifen } 20 \text { mg }(9,872)\end{array}$ & 5 & $\begin{array}{l}>1.6 \% 5 \text {-year risk, } \\
\text { postmenopausal } \\
\text { women }\end{array}$ & $\begin{array}{l}\text { Unblinded, no } \\
\text { follow-up }\end{array}$ & $81(60.8-96.6)$ \\
\hline PEARL ${ }^{21}$ & 8,856 & $200 \mathrm{I}-07$ & $\begin{array}{l}\text { Placebo }(2,852) \\
\text { Lasofoxifene } 0.50 \mathrm{mg}(2,852) \\
\text { Lasofoxifene } 0.25 \mathrm{mg}(2,852)\end{array}$ & 5 & $\begin{array}{l}\text { Normal risk, } \\
\text { postmenopausal } \\
\text { women with } \\
\text { osteoporosis }\end{array}$ & $\begin{array}{l}\text { Blinded, no } \\
\text { follow-up }\end{array}$ & $59.6(58.8-60.1)$ \\
\hline GENERATIONS 22 & 9,354 & 2004-09 & $\begin{array}{l}\text { Placebo }(4,678) \\
\text { Arzoxifene } 20 \mathrm{mg}(4,676)\end{array}$ & 4 & $\begin{array}{l}\text { Normal risk, } \\
\text { postmenopausal } \\
\text { with low BMD or } \\
\text { osteoporosis }\end{array}$ & $\begin{array}{l}\text { Unblinded, no } \\
\text { follow-up }\end{array}$ & $54.3(28.3-56.1)$ \\
\hline
\end{tabular}

Note: Trials are sorted according to agent and recruitment period. Reprinted with permission from Elsevier (The Lancet, 20I3;38I:1827-I834, Cuzick J, Sestak I, Bonanni B, et al. Selective oestrogen receptor modulators in prevention of breast cancer: an updated meta-analysis of individual participant data). ${ }^{16}$

Abbreviations: IBIS, International Breast cancer Intervention Study; MORE, Multiple Outcomes of Raloxifene Evaluation; CORE, Continuing Outcomes Relevant to Evista; RUTH, Raloxifene Use for The Heart; STAR, Study of Tamoxifen And Raloxifene; CHD, coronary heart disease; BMD, bone mineral density; PEARL, Postmenopausal Evaluation and Risk Reduction With Lasofoxifene; FU, follow-up.

All breast cancers (including ductal carcinoma in situ [DCIS]) were significantly reduced by $0.5 \mathrm{mg} /$ day lasofoxifene when compared to placebo, whereas no significant effect was seen for women receiving $0.25 \mathrm{mg} /$ day lasofoxifene, although a beneficial trend was seen. An even greater reduction was seen for invasive ER-positive breast cancer with $0.5 \mathrm{mg} /$ day lasofoxifene. Furthermore, lasofoxifene significantly reduced major coronary events, strokes, and both vertebral and non-vertebral fractures, so may be ideal for prevention where the total benefit/harm balance is particularly important. Overall, there were no differences between the groups in terms of other serious adverse events.

The GENERATIONS trial evaluated the effect of arzoxifene ( $20 \mathrm{mg}$ /day) versus placebo in 9,354 postmenopausal women with osteoporosis (Table 1). ${ }^{22}$ Arzoxifene reduced all breast cancer occurrences by $58 \%$. The incidence of DCIS was substantially but nonsignificantly reduced. Arzoxifene also reduced vertebral fractures by $41 \%$ but an increase was seen for thromboembolic events, hot flushes, muscle cramps, and gynecological events.

A recently published SERM overview ${ }^{16}$ is the only comprehensive analysis of all SERM prevention trials to date. The meta-analysis reported on a substantial update on all SERM trials with long-term follow-up (except for the arzoxifene and lasofoxifene trials) and the results clearly showed that all SERMs significantly reduce the incidence on invasive ER-positive breast cancer (Figure 1). However, as seen in all individual trials as well, no effect of SERMs was seen for ERnegative breast cancers, and it is clear that new approaches have to be found to reduce the incidence of these cancers in a high-risk population. Another important finding was that benefits from SERMs were not only seen during the active 5 years of follow-up but also after treatment was completed, indicating a long-term effect of SERMs in the prevention of 


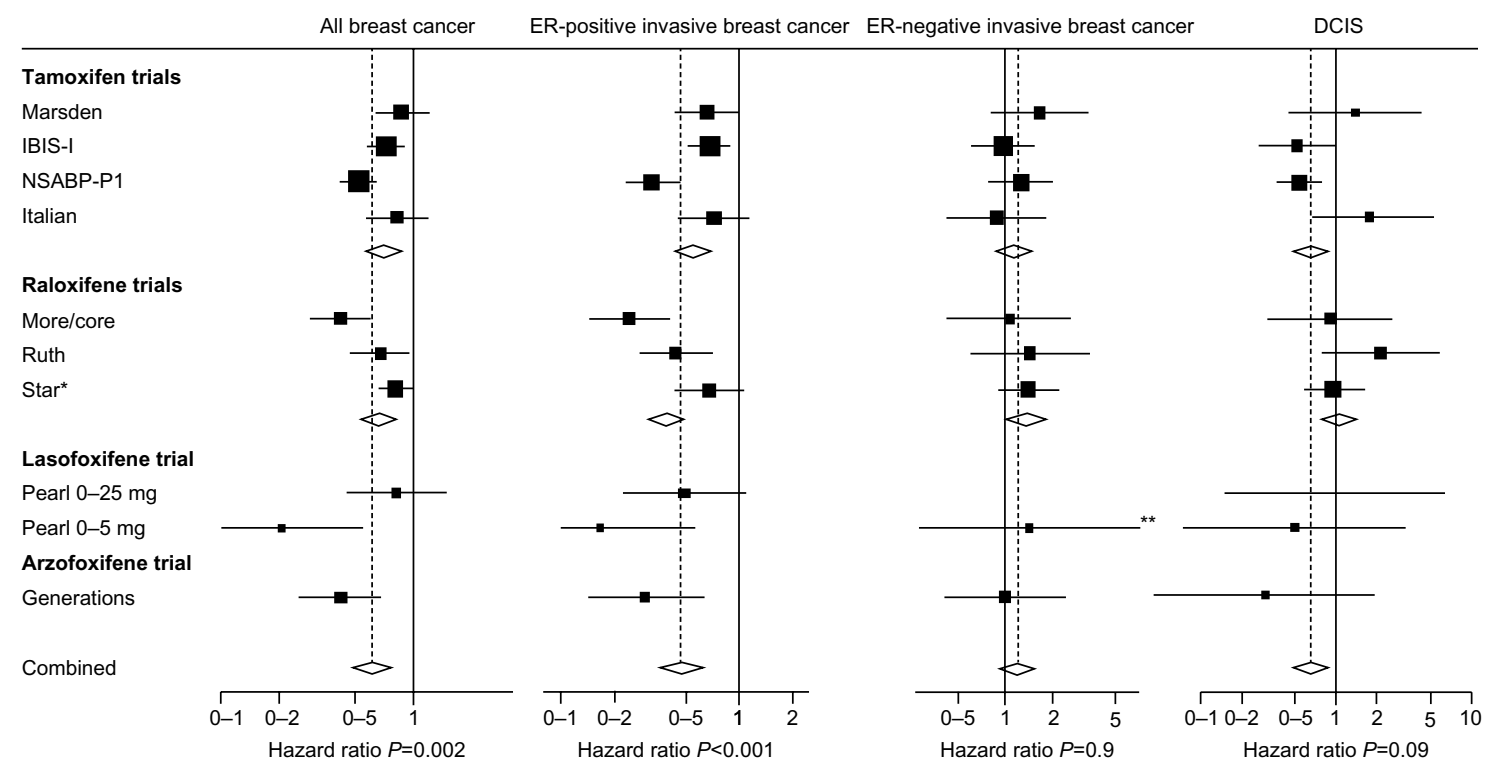

Figure I Forest plots for all breast cancer, ER+/ER- invasive breast cancer, and DCIS according to SERM and trial.

Notes: *Adjusted by overall tamoxifen effect to give raloxifene vs placebo comparison, STAR data not included in overall effect; **pooled data. Reprinted with permission from Elsevier (The Lancet, 2013;38I:1827-1834, Cuzick J, Sestak I, Bonanni B, et al. Selective oestrogen receptor modulators in prevention of breast cancer: an updated meta-analysis of individual participant data). ${ }^{16}$

Abbreviations: ER, estrogen receptor; IBIS, International Breast cancer Intervention Study; MORE, Multiple Outcomes of Raloxifene Evaluation; CORE, Continuing Outcomes Relevant to Evista; RUTH, Raloxifene Use for The Heart; STAR, Study of Tamoxifen And Raloxifene; ER, estrogen receptor; SERM, selective estrogen receptor modulator; DCIS, ductal carcinoma in situ; PEARL, Postmenopausal Evaluation and Risk Reduction With Lasofoxifene.

breast cancer. The decision to use a SERM for breast cancer prevention should not solely be based on the effect on breast cancer incidence. Adverse effects, notably thromboembolic events and, for tamoxifen only, endometrial cancers, have to be taken into account when assessing the risk-benefit ratio for each individual patient. This decision making is a very complex, individual, and complicated matter, but an improved risk-benefit ratio for SERMs might be indicated for women who are at high risk of breast cancer at any age compared to those with average risk. However, currently, the only chemopreventive option for premenopausal women is tamoxifen. Recently, in the UK, the National Institute for Health and Care Excellence has published updated guidelines for the use of tamoxifen (and raloxifene) for women at high risk of developing breast cancer, although these drugs are not licensed for this purpose in the UK. ${ }^{23}$

\section{Aromatase inhibitors}

Third-generation AIs (anastrozole, letrozole, and exemestane) act via the inhibition of the cytochrome P450 enzyme aromatase, which converts androgens into estrogens. ${ }^{24}$ In metastatic disease, many trials have shown that AIs have great benefits when compared to megestrol acetate. Most of the use of AIs in the preventive setting derives from adjuvant studies in postmenopausal women with early breast cancer.

\section{Adjuvant trials}

The use of AIs has been widely investigated in postmenopausal women with early breast cancer (Table 1). ${ }^{25-30}$ Several different study designs have been investigated, and most trials used the AI as an initial treatment, ${ }^{27}$ some used it after 2-3 years of tamoxifen, ${ }^{26,28,30}$ or as an extended treatment after 5 years of tamoxifen use. ${ }^{29,31}$ All these trials, irrespective of the study design, have shown a consistent reduction in contralateral breast cancer. Specifically, the Anastrozole, Tamoxifen, Alone or in Combination trial showed that 5 years of anastrozole use significantly improved disease-free survival when compared to tamoxifen, ${ }^{25,32-34}$ and the updated results confirmed the better efficacy of anastrozole over tamoxifen as initial adjuvant treatment in postmenopausal women with early breast cancer. ${ }^{33}$

Based on these findings, AIs are being routinely used in the treatment of breast cancer. Furthermore, a recently conducted meta-analysis of adjuvant trials with AIs indicated that these agents consistently showed lower recurrence rates when compared to tamoxifen, either as initial therapy or after 2-3 years of tamoxifen use. ${ }^{35}$ This overview provides clear evidence that AIs achieve significant reductions in breast cancer recurrence.

\section{Prevention trials}

The use of AIs in the preventive setting has not yet been extensively investigated. Two main prevention trials have 
reported their results to date. The Mammary Prevention 3 (MAP3) trial compared the steroidal AI exemestane with placebo in postmenopausal women at increased risk of breast cancer, whereas the International Breast cancer Intervention Study-II (IBIS-II) trial investigated the use of anastrozole in a similar population.

The MAP3 trial enrolled over 4,500 postmenopausal women who were at risk of developing breast cancer and randomized them to either exemestane or placebo for 5 years. After a median of 35 months of follow-up, 11 invasive breast cancers were found with exemestane versus 32 with placebo, resulting in a $65 \%$ reduction of invasive breast cancers with exemestane. ${ }^{36}$ No effect was seen for ER-negative disease. No statistically significant differences were found between treatment arms for adverse events, suggesting a good risk-benefit profile. However, this trial had some limitations, most importantly the short follow-up period of only 35 months. Due to this immaturity, the MAP3 trial does not allow for any conclusion of the safety and long-term efficacy of this drug. Furthermore, after publications of the results, women on placebo were offered the opportunity to cross-over to exemestane, which does not permit the assessment of long-term efficacy of this drug, including overall, and specifically, breast cancer mortality.

The IBIS-II trial compares anastrozole with placebo in postmenopausal women at increased risk of breast cancer. The main results were recently reported after a median of 5 years of follow-up, ${ }^{37}$ and a highly significant reduction of invasive ER-positive breast cancers was seen with anastrozole compared with placebo in this high-risk population $(58 \%, \mathrm{HR}$ $=0.42[0.25-0.71])$, which was similar to the results reported in the MAP3 trial. As in the MAP3 trial, no effect of anastrozole was found for ER-negative breast cancer. Vasomotor and musculoskeletal side effects were increased with the use of anastrozole, and these side effects were also reported by many women on placebo. Strengths of the IBIS-II trial were the large number of breast cancers reported and the median follow-up of 5 years. All women remain blinded for long-term follow-up, which is important since overall long-term efficacy of anastrozole, or any other AI, for healthy postmenopausal women at increased risk of breast cancer has not yet been established.

Overall, the reported reductions for both exemestane and anastrozole were larger than those seen for tamoxifen or any other SERMs, and these results indicate that both drugs are attractive options for breast cancer prevention in postmenopausal women at increased risk of the disease. For premenopausal women, the only option remains tamoxifen. Tamoxifen, exemestane, and anastrozole are all out of patent, and registering these drugs for use in the preventive setting will most probably not be marketed. Although approved by several regulatory authorities for the use in the preventive setting, these drugs, despite their effectiveness, are unfortunately not widely accepted as breast cancer preventive drugs by high-risk women and their physicians. Reasons for the low uptake of chemopreventive agents, SERMs or AIs, are fear of side effects, general practitioners not being aware of chemopreventive options for high-risk women, and the drug industry not promoting the drugs for primary prevention.

\section{Other agents}

Other agents have emerged, although initially developed for other diseases, which might be useful for the prevention of breast cancer in high-risk women. New generations of chemopreventive agents that do not modulate the endocrine pathways have been studied recently.

\section{Metformin}

Metformin is a safe drug widely used by millions of people for the treatment of non-insulin-dependent diabetes. It works by targeting the enzyme AMP-activated protein kinase, which induces muscles to take up glucose from the blood. The rationale for the use of metformin in breast cancer prevention comes from obesity being an independent risk factor for breast cancer in postmenopausal women. Many studies have shown that long-term use of metformin may have a beneficial effect on breast cancer risk. Small biomarker studies in women with breast cancer in a placebo-controlled setting are ongoing and these results may lead to larger chemoprevention trials with metformin.

\section{Bisphosphonates}

Bisphosphonates were originally developed for the treatment of osteoporosis and are commonly used in the breast cancer setting in controlling bone loss induced by AIs and chemotherapy. In addition, adjuvant breast cancer trials evaluating the oral bisphosphonate clodronate suggested a reduction in cancer recurrence, but the findings were mixed. ${ }^{38}$ Several studies have now shown that bisphosphonates reduce breast cancer in postmenopausal women by around $30 \%$. $^{38,39}$ These findings require a cautious interpretation since bisphosphonates are given to women with a low bone mineral density and these women are at a decreased risk of breast cancer. However, these agents are well tolerated, and primary prevention trials are needed to fully investigate the riskbenefit ratio of these agents for breast cancer prevention. It is not clear if they are suitable for premenopausal women. 


\section{Nonsteroidal anti-inflammatory drugs}

Long-term follow-up of randomized trials using aspirin in the prevention of vascular disease showed that daily use reduced the incidence of colorectal cancer and several other cancers. Evidence from case-control and cohort studies indicates a reduction of breast cancer risk by about $10 \%$ for aspirin and possibly a little more for ibuprofen. ${ }^{40,41}$ Similar results have been found with other nonsteroidal anti-inflammatory drugs (NSAIDs) and COX-2 inhibitors. ${ }^{42}$ Although an effect of NSAIDs on breast cancer risk reduction is too small to make a conclusive decision regarding its sole use in the prevention of breast cancer, these drugs may be part of a broad intervention approach, specifically since a beneficial effect is seen on colorectal cancers and cardiovascular disease. ${ }^{43}$

The IBIS-III trial will integrate several chemopreventive agents in one trial. This trial will directly address the issue of late recurrence in postmenopausal breast cancer survivors and will include integrated biological studies to explore mechanisms of drug action and to identify which patients are at greatest risk of late recurrence. Specifically, this trial will attempt to determine which cancers are most susceptible to control with metformin and/or an AI and/or a bisphosphonate in a $2 \times 2 \times 2$ factorial trial. Of particular interest will be any possible positive synergism between these agents.

\section{Conclusion}

The prevention of ER-positive breast cancer with SERMs is well established, and they are the only option for premenopausal women to date. However, despite their efficacy, these drugs have not been well accepted as preventive agents by high-risk women or clinicians, mostly because of adverse events. For postmenopausal women, the AIs have been established for the treatment of breast cancer and recent publications also favor those drugs over SERMs in the preventive setting. Both the MAP3 and IBIS-II trials have reported a significant reduction for invasive breast cancer in postmenopausal women in the preventive setting.

Biomarkers are important for the identification of women at high risk, and breast density is currently the most attractive measure. Breast density is a well-established risk factor for breast cancer and it has been shown that change in breast density might predict drug effectiveness and therefore be a useful surrogate marker. ${ }^{44}$ Similarly, a recent publication has reported that mammographic density during the use of adjuvant endocrine treatment was a significant predictor for recurrence in women with ER-positive breast cancer. ${ }^{45}$
The prevention of incidence or recurrence of ER-negative disease remains a huge challenge, and other agents have to be developed for the prevention of these tumors. Recent research interests have been in so-called non-endocrine-based pathways, such as epidermal growth factor 1 or human epidermal growth factor. NSAIDs, ${ }^{46} \mathrm{COX}-2$ inhibitors, ${ }^{47,48}$ retinoids, rexinoids, and statins ${ }^{49,50}$ may also protect against both receptor positive and receptor negative tumors, but results only from observational studies or adjuvant studies are available at the moment, and there are still inconsistencies. A new agent, deguelin, which prevents mammary tumorigenesis, has shown important advances in the prevention of ER-negative breast cancer. ${ }^{51}$

Of great interest are the single nucleotide polymorphisms (SNIPs) that individually have minor effects of risk but are common. Some women will have several of these SNIPs to have an impact on their breast cancer risk, especially in combination with mammographic density and other known factors. An assessment of how SNIPs might improve risk assessment among high-risk women is needed for better targeting of preventive therapy. In a recent study, Cuzick et al evaluated a panel of 15 SNIPs and found that they are useful for refining risk estimates in women at high risk of developing breast cancer. ${ }^{52}$

In conclusion, there are many options for the prevention of ER-positive breast cancer, specifically in postmenopausal women who can be given a SERM or an AI. For premenopausal women, only tamoxifen can be potentially used as a preventive agent as AIs are not indicated in this group of women. It remains unclear how to prevent the incidence of ER-negative breast cancer, which occurs mostly in premenopausal women, and more research is needed to specifically target this unsolved matter.

\section{Disclosure}

The author reports no conflicts of interest in this work.

\section{References}

1. Ferlay J, Soerjomataram I, Ervik M, et al. GLOBOCAN 2012 v1.0, Cancer Incidence and Mortality Worldwide: IARC CancerBase No 11 [Internet]. Lyon: International Agency for Research on Cancer; 2013

2. Cuzick J. Aromatase inhibitors for breast cancer prevention. J Clin Oncol. 2005;23:1636-1643.

3. Tseng M, Weinberg CR, Umbach DM, Longnecker MP. Calculation of population attributable risk for alcohol and breast cancer (United States). Cancer Causes Control. 1999;10:119-123.

4. Sestak I, Cuzick J. Breast cancer chemoprevention. Oncol Rev. 2008;2: 221-226.

5. Tamoxifen for early breast cancer: an overview of the randomised trials. Early Breast Cancer Trialists' Collaborative Group. Lancet. 1998;351: $1451-1467$. 
6. Cuzick J, Powles T, Veronesi U, et al. Overview of the main outcomes in breast-cancer prevention trials. Lancet. 2003;361:296-300.

7. Powles T, Eeles R, Ashley S, et al. Interim analysis of the incidence of breast cancer in the Royal Marsden Hospital tamoxifen randomised chemoprevention trial. Lancet. 1998;352:98-101.

8. Powles TJ, Ashley S, Tidy A, Smith IE, Dowsett M. Twenty-year follow-up of the Royal Marsden randomized, double-blinded tamoxifen breast cancer prevention trial. J Natl Cancer Inst. 2007;99: 283-290.

9. Cuzick J, Forbes J, Edwards R, et al. First results from the International Breast Cancer Intervention Study (IBIS-I): a randomised prevention trial. Lancet. 2002;360:817-824.

10. Cuzick J, Forbes JF, Sestak I, et al. Long-term results of tamoxifen prophylaxis for breast cancer - 96-month follow-up of the randomized IBIS-I trial. J Natl Cancer Inst. 2007;99:272-282.

11. Veronesi U, Maisonneuve P, Rotmensz N, et al. Tamoxifen for the prevention of breast cancer: late results of the Italian Randomized Tamoxifen Prevention Trial among women with hysterectomy. J Natl Cancer Inst. 2007;99:727-737.

12. Veronesi U, Maisonneuve P, Sacchini V, et al. Tamoxifen for breast cancer among hysterectomised women. Lancet. 2002;359:1122-1124.

13. Fisher B, Costantino JP, Wickerham DL, et al. Tamoxifen for the prevention of breast cancer: current status of the National Surgical Adjuvant Breast and Bowel Project P-1 study. J Natl Cancer Inst. 2005;97:1652-1662.

14. Fisher B, Costantino JP, Wickerham DL, et al. Tamoxifen for prevention of breast cancer: report of the National Surgical Adjuvant Breast and Bowel Project P-1 Study. J Natl Cancer Inst. 1998;90:1371-1388.

15. Veronesi U, Maisonneuve P, Costa A, et al. Prevention of breast cancer with tamoxifen: preliminary findings from the Italian randomised trial among hysterectomised women. Italian Tamoxifen Prevention Study. Lancet. 1998;352:93-97.

16. Cuzick J, Sestak I, Bonanni B, et al. Selective oestrogen receptor modulators in prevention of breast cancer: an updated meta-analysis of individual participant data. Lancet. 2013;381:1827-1834.

17. Cummings SR, Eckert S, Krueger KA, et al. The effect of raloxifene on risk of breast cancer in postmenopausal women: results from the MORE randomized trial. Multiple Outcomes of Raloxifene Evaluation. JAMA. 1999;281:2189-2197.

18. Martino S, Cauley JA, Barrett-Connor E, et al. Continuing outcomes relevant to Evista: breast cancer incidence in postmenopausal osteoporotic women in a randomized trial of raloxifene. J Natl Cancer Inst. 2004;96:1751-1761.

19. Barrett-Connor E, Mosca L, Collins P, et al. Effects of raloxifene on cardiovascular events and breast cancer in postmenopausal women. N Engl J Med. 2006;355:125-137.

20. Vogel VG, Costantino JP, Wickerham DL, et al. Effects of tamoxifen vs raloxifene on the risk of developing invasive breast cancer and other disease outcomes: the NSABP Study of Tamoxifen and Raloxifene (STAR) P-2 Trial. JAMA. 2006;295(23):2727-2741

21. Cummings SR, Ensrud K, Delmas PD, et al. Lasofoxifene in postmenopausal women with osteoporosis. N Engl J Med. 2010;362:686-696.

22. Cummings SR, McClung M, Reginster JY, et al. Arzoxifene for prevention of fractures and invasive breast cancer in postmenopausal women. J Bone Miner Res. 2011;26:397-404.

23. NICE: Familial Breast Cancer; 2013. Available from: guidance.nice org.uk/cg164 NICE.

24. Richards JA, Petrel TA, Brueggemeier RW. Signaling pathways regulating aromatase and cyclooxygenases in normal and malignant breast cells. J Steroid Biochem Mol Biol. 2002;80:203-212.

25. Baum M, Budzar AU, Cuzick J, et al. Anastrozole alone or in combination with tamoxifen versus tamoxifen alone for adjuvant treatment of postmenopausal women with early breast cancer: first results of the ATAC randomised trial. Lancet. 2002;359:2131-2139.

26. Boccardo F, Rubagotti A, Puntoni M, et al. Switching to anastrozole versus continued tamoxifen treatment of early breast cancer: preliminary results of the Italian Tamoxifen Anastrozole Trial. J Clin Oncol. 2005;23:5138-5147.
27. Coates AS, Keshaviah A, Thürlimann B, et al. Five years of letrozole compared with tamoxifen as initial adjuvant therapy for postmenopausal women with endocrine-responsive early breast cancer: update of study BIG 1-98. J Clin Oncol. 2007;25:486-492.

28. Coombes RC, Hall E, Gibson LJ, et al. A randomized trial of exemestane after two to three years of tamoxifen therapy in postmenopausal women with primary breast cancer. $N$ Engl J Med. 2004;350:1081-1092.

29. Goss PE, Ingle JN, Martino S, et al. A randomized trial of letrozole in postmenopausal women after five years of tamoxifen therapy for early-stage breast cancer. $N$ Engl J Med. 2003;349:1793-1802.

30. Jakesz R, Jonat W, Gnant M, et al. Switching of postmenopausal women with endocrine-responsive early breast cancer to anastrozole after 2 years' adjuvant tamoxifen: combined results of ABCSG trial 8 and ARNO 95 trial. Lancet. 2005;366:455-462.

31. Mamounas E, Jeong J-H, Wickerham DL, et al. Benefit from exemestane (EXE) as extended adjuvant therapy after 5 years of tamoxifen (TAM): intent-to-treat analysis of NSABP B-33. Breast Cancer Res Treat. 2006; $100:$ S22.

32. Baum M, Buzdar A, Cuzick J, et al. Anastrozole alone or in combination with tamoxifen versus tamoxifen alone for adjuvant treatment of postmenopausal women with early-stage breast cancer: results of the ATAC (Arimidex, Tamoxifen Alone or in Combination) trial efficacy and safety update analyses. Cancer. 2003;98:1802-1810.

33. Arimidex, Tamoxifen Alone or in Combination (ATAC) Trialists' Group, Forbes JF, Cuzick J, et al. Effect of anastrozole and tamoxifen as adjuvant treatment for early-stage breast cancer: 100-month analysis of the ATAC trial. Lancet Oncol. 2008;9:45-53.

34. Howell A, Cuzick J, Baum M, et al. Results of the ATAC (Arimidex, Tamoxifen, Alone or in Combination) trial after completion of 5 years' adjuvant treatment for breast cancer. Lancet. 2005;365:60-62.

35. Dowsett M, Cuzick J, Ingle J, et al. Meta-analysis of breast cancer outcomes in adjuvant trials of aromatase inhibitors versus tamoxifen. $J$ Clin Oncol. 2010;28:509-518.

36. Goss PE, Ingle JN, Alés-Martínez JE, et al. Exemestane for breastcancer prevention in postmenopausal women. N Engl J Med. 2011;364: 2381-2391.

37. Cuzick J, Sestak I, Forbes JF, et al. Anastrozole for prevention of breast cancer in high-risk postmenopausal women (IBIS-II): an international, double-blind, randomised placebo-controlled trial. Lancet. 2014;383(9922):1041-1048.

38. Chlebowski RT, Col N. Bisphosphonates and breast cancer prevention. Anticancer Agents Med Chem. 2012;12:144-150.

39. Rennert G, Pinchev M, Rennert HS. Use of bisphosphonates and risk of postmenopausal breast cancer. J Clin Oncol. 2010;28:3577-3581.

40. Terry MB, Gammon MD, Zhang FF, et al. Association of frequency and duration of aspirin use and hormone receptor status with breast cancer risk. JAMA. 2004;291:2433-2440.

41. Holmes MD, Chen WY, Li L, Hertzmark E, Spiegelman D, Hankinson SE. Aspirin intake and survival after breast cancer. J Clin Oncol. 2010;28:1467-1472.

42. Li Y, Brasky TM, Nie J, et al. Use of nonsteroidal anti-inflammatory drugs and survival following breast cancer diagnosis. Cancer Epidemiol Biomarkers Prev. 2012;21:239-242.

43. Wald NJ, Morris JK, Law MR. Aspirin in the prevention of cancer. Lancet. 2011;377:1649; author reply 1651-1652.

44. Cuzick J, Warwick J, Pinney E, et al. Tamoxifen-induced reduction in mammographic density and breast cancer risk reduction: a nested case-control study. J Natl Cancer Inst. 2011;103:744-752.

45. Kim J, Han W, Moon HG, et al. Breast density change as a predictive surrogate for response to adjuvant endocrine therapy in hormone receptor positive breast cancer. Breast Cancer Res. 2012;14:R102.

46. Rahme E, Ghosn J, Dasgupta K, Rajan R, Hudson M. Association between frequent use of nonsteroidal anti-inflammatory drugs and breast cancer. BMC Cancer. 2005;5:159.

47. Harris RE, Beebe-Donk J, Alshafie GA. Reduction in the risk of human breast cancer by selective cyclooxygenase-2 (COX-2) inhibitors. $B M C$ Cancer. 2006;6:27. 
48. Mazhar D, Ang R, Waxman J. COX inhibitors and breast cancer. Br J Cancer. 2006;94:346-350.

49. Eliassen AH, Colditz GA, Rosner B, Willett WC, Hankinson SE. Serum lipids, lipid-lowering drugs, and the risk of breast cancer. Arch Intern Med. 2005; 165:2264-2271.

50. Esserman LJ, Campbell M, Shoemaker M. Breast cancer inhibition by statins. Proc Am Soc Clin Oncol. 2004;2004:97.
51. Murillo G, Peng X, Torres KE, Mehta RG. Deguelin inhibits growth of breast cancer cells by modulating the expression of key members of the Wnt signaling pathway. Cancer Prev Res (Phila). 2009;2:942-950.

52. Cuzick J, Brentnall AR, Segala C, et al. Use of a SNP panel to refine risk estimates in women at high risk of breast cancer: results from two randomized tamoxifen prevention trials. J Clin Oncol. 2014; 32(Suppl; abstr 1519).

\section{Publish your work in this journal}

Cancer Management and Research is an international, peer-reviewed open access journal focusing on cancer research and the optimal use of preventative and integrated treatment interventions to achieve improved outcomes, enhanced survival and quality of life for the cancer patient. The journal welcomes original research, clinical \& epidemiological studies, reviews \& evaluations, guidelines, expert opinion \& commentary, case reports \& extended reports. The manuscript management system is completely online and includes a very quick and fair peerreview system, which is all easy to use. Visit http://www.dovepress.com/ testimonials.php to read real quotes from published authors.

Submit your manuscript here: http://www.dovepress.com/cancer-management-and-research-journal 